\title{
Not So Special After All? Daniels and the Social Determinants of Health
}

Key words: Health, Justice, Social determinants of health, Norman Daniels

Word count:

Dr James Wilson

Centre for Professional Ethics

Keele University

Keele

Staffordshire, ST5 5BG

UK

j.g.wilson@peak.keele.ac.uk

Tel: 00441782584085

Fax: 00441782584239

(I am now at UCL - current email address is james-gs.wilson@ucl.ac.uk) 


\section{ABSTRACT}

Just Health is an ambitious book, in which Norman Daniels attempts to bring together in a single framework all his work on health and justice from the past 25 years. One major aim is to reconcile his earlier work on the special moral importance of healthcare with his later work on the social determinants of health. In his earlier work, Daniels argued that healthcare is of special moral importance because it protects opportunity. In this later work, Daniels argues that the social determinants of health (which in fact tend to have a larger effect on health outcomes than healthcare does) should also be considered special. This paper argues that it is a mistake to base a theory of justice for health on the claim that health (or the social determinants of health) are 'special', for three reasons. First, once we realise that health is to a large part socially determined by features such as distribution of income, which are also of independent importance for justice, we cannot talk about a theory of justice for health in isolation from an overall theory of justice. Second, when we are trying to work out the place of health in a general theory of justice, being told that health (or the social determinants of health) is special is unhelpful. The relevant starting point should rather be whether health matters in a fundamental way for justice, or whether it matters merely for the effects it has on those goods which are of 
fundamental importance for justice. Third, treating the social determinants of health as special would in fact be counterproductive in terms of the broad approach to justice Daniels favours.

\section{INTRODUCTION}

Just Health [1] is an ambitious book, in which Norman Daniels attempts to bring together in a single framework all his work on health and justice from the past 25 years. The obvious question is whether the whole is equal to the sum of the parts. I shall argue that, at least when it comes to the social determinants of health, it is rather less. The extensions to his theory of justice in healthcare which Daniels makes to take account of the social determinants of health end up revealing that his approach to justice in health and healthcare is deeply flawed.

I shall proceed as follows. First I shall briefly distinguish health, healthcare and the social determinants of health, and will attempt to elucidate what Daniels means by special moral importance. Second, I give a brief exposition of Daniels' account of the special moral importance of healthcare in his earlier work Just Health Care.[2] Third, I explain why (as Daniels acknowledges) the literature on the social determinants of health reveals an important problem with this argument, and explain how Daniels 
attempts to extend his 'specialness' argument so that it is not only healthcare, but also health and the social determinants of health which are said to be special. Finally, I argue that it is a mistake to base a theory of justice for health on the claim that health (or the social determinants of health) are 'special', for three reasons. First, once we realise that health is to a large part socially determined by features such as distribution of income which are also of independent importance for justice - we cannot talk about a theory of justice for health in isolation from an overall theory of justice. Second, when we are trying to work out the place of health in a general theory of justice, being told that health (or the social determinants of health) is special is unhelpful. The relevant starting point should rather be whether health matters in a fundamental way for justice, or whether it matters merely for the effects it has on those goods which are of fundamental importance for justice. Third, treating the social determinants of health as special would in fact be counterproductive in terms of the broad approach to justice Daniels favours.

\section{DEFINING TERMS}

Daniels argues that we should define health as the "absence of... deviation from the natural functional organization of a typical member of a species.'[3] Various factors will determine how healthy a given individual is. Clearly, genetic factors will often play a role, as will exposure to 
communicable diseases. This article focuses on the role of healthcare and of the social determinants of health. By healthcare I mean, roughly, interventions by qualified professionals with the aim of either restoring health (for example, prescribing a drug), or preventing damage to health (for example, provision of safe-sex advice; or dietary advice to people at risk of developing type-2 diabetes).

By the social determinants of health I mean, roughly, all those factors which affect health and (a) have a social and systemic as opposed to a natural or episodic cause, and (b) fall outside the narrow sphere of healthcare. The social determinants of health include, for instance, workplace stress, social exclusion, and the inequality of distribution of income in society [4], but not the provision of medical treatment. There will of course be some grey areas where we are unsure whether to class something as healthcare or as a social determinant of health. But nothing in what follows depends on drawing such a sharp distinction. (Indeed my argument is compatible with the claim that all healthcare should be classified as social determinants of health.)

One thing which will prove crucial in what follows is the idea of "special moral importance" (specialness for short). In Just Health Care, Daniels frequently talks about the specialness of healthcare, and in Just Health he broadens his focus so that it is not just healthcare, but also health itself and the social determinants of health which are said to be of special moral 
importance. When elucidating what he means by the question of whether health or healthcare is of special moral importance, Daniels makes claims like the following:

My focus on the question [of whether health is of special moral importance] then and now is driven by the common observation that people who tolerate vast inequalities in wealth and power are often morally outraged when those who are ill cannot get care because they cannot pay for it. People who emphatically reject the general Marxist distributive principle, "From each according to his ability, to each according to his needs," embrace at least the second part of it when applied to health care.[5]

However nowhere does Daniels give a precise account of what is entailed by the claim that something is of special moral importance in his sense. Segall, in a helpful recent article puts forward the following account of what it is to treat healthcare as special, which seems to have Daniels's agreement. On this view, to say that healthcare is special "is to imply that health care resources ought to be allocated in isolation from the distributions of other social goods.”[6] It follows from this that "Poor people's entitlement to health care must not be restricted on account of their inferior financial 
standing. But ... it also forbids discriminating against the rich in access to medical care. More generally, the specialness thesis forbids discriminating against members of society who are relatively well off with regard to goods other than health. This is part of what it means to allocate health care in isolation from other distributions.'[7]

In default of any other account, I shall assume that this is the best way to interpret Daniels. Regardless of whether this is the right way to interpret Daniels, it is clear that he does not think that to claim that health, healthcare or the social determinants of health are of special moral importance is to claim that health, healthcare or the social determinants of health matter for justice for their own sake. For he explicitly argues against the claim that we should consider health to be a primary good: "The special importance and unequal distribution of health-care needs, like educational needs, are acknowledged by connecting the needs to institutions that provide for fair equality of opportunity. But opportunity, not health care or education remains the primary social good."[8] Hence on Daniels's account opportunity matters in its own right for justice, but health matters only for the effect it has on opportunity. 


\section{DANIELS'S ARGUMENT FOR THE SPECIALNESS OF HEALTHCARE}

In Just Health Care Daniels argues that the correct explanation of the common intuition that there is something 'special' about healthcare is the protective effect that healthcare has on opportunity. Crucially, Daniels argues that a commitment to equal opportunities commits us to two things: first that each person should have a fair share of the normal opportunity range, where the normal opportunity range is "the array of life plans reasonable persons in [a given society] are likely to construct for themselves".[9] Second, that a person's fair share of the opportunity range is determined by their talents and skills alone. Given these assumptions, Daniels argues that we should see disease and disability as limitations on a person's normal opportunity range. In short, health is a necessary condition for a person's being able to access the normal opportunity range for their talents, healthcare protects health, and therefore a commitment to fair equality of opportunity commits us to treating healthcare as 'special'.

There are a number of objections that one might make to this argument. First, it is far from obvious that it is a commitment to equal opportunity rather than anything else, which provides the best explanation for the common intuition that there is something special about healthcare.[10] 
Moreover the way we currently distribute our health care budgets is very different from what Daniels's approach would commit us to: as Segall puts it, "Most patients treated by health care systems are individuals in the twilight of their lives... An often-cited figure is that, in the US, $30 \%$ of health care expenditure is currently spent on patients in the last six months of their life... Health care in that case cannot be said to provide opportunity, equal or otherwise, to pursue life plans. The effect of successful treatment of patients who are in the last weeks of their lives is not so much that of giving them opportunity to pursue their life plans, but rather that of alleviating their pain and suffering and that of postponing death as long as possible."[11]

But I shall leave these problems on one side here in order to focus on a different problem. Daniels's argument implicitly assumes that healthcare is the major factor which affects health. However this claim is false. Even countries like the UK that have a nationalised healthcare system which is free at the point of access show a large socioeconomic gradient in health, so clearly equal access to healthcare can only be one factor in overall health achievement. And as Daniels now acknowledges, a large body of social sciences literature has shown that factors like how hierarchical our workplaces are, how much social capital there is in society, and how unequal incomes are all have a major impact on health: "Health is produced not just by having access to treatment, but to a measurably great extent, by the cumulative experience of social conditions across the lifecourse. When a 
60 year old patient presents to the emergency room with a heart attack to receive medical treatment, that encounter represents the results of bodily insults that accumulated over a lifetime. Medical care is, figuratively speaking, 'the ambulance at the bottom of the cliff."'[12] So if we want to protect health we need to focus on issues such as the way we work, and the levels of income inequality in society, in addition to ensuring fair access to healthcare.[13,14]

\section{DANIELS'S NEW ACCOUNT OF THE VALUE OF}

\section{HEALTH}

Clearly if Daniels's justification for taking healthcare to be special is that healthcare protects health, and that health is necessary for the enjoyment of a normal opportunity range, then parity of reasoning would suggest that he should take the social determinants of health to be special, given that both equally determine opportunity. And this is what Daniels does. In Just Health, healthcare is taken to be "but one among a broader set of health needs."[15] And whilst the earlier work refers only to healthcare as special, Just Health broadens things out so that both health and health needs (which include those health needs identified by the social determinants of health literature) are now also deemed to be special. 
But the claim that the social determinants of health are special is much more problematic than Daniels seems to realise. Treating healthcare as special implies focusing separately on the allocation of healthcare, to ensure that other factors (such as how rich someone is) do not adversely affect their healthcare provision. Treating healthcare as special in this way could make for a reasonable policy. Given that healthcare is valued only for its contribution to health, it can reasonably be allocated in isolation from other goods. However the social determinants of health are not valued solely for their contribution to health. For example, the distribution of incomes in society is an important social determinant of health; but clearly we have justice-based reasons to care about the distribution of incomes which are not reducible to the effect that such distributions have on health.

It follows that treating income as special in virtue of its effects on health would require us to override distributions of incomes which would otherwise have been just, in order to ensure desired distributions of health. Treating income as special would require us to identify and to implement a just distribution of incomes-as-they-affect-health separately from the question of what a just distribution of incomes considered on their own would be. But this seems implausible. Even if we were sure that a particular distribution of incomes was necessary to bring about a certain desired pattern of health outcomes in a population, it would be a further question about whether justice required us to institute this distribution of incomes. 
For there are goods other than health which are important from the perspective of justice, and doing something that imposes a particular pattern of health outcomes will only sometimes coincide with what justice tout court recommends.

Someone might think that health is so important that all the social determinants of health should be allocated separately in such a way as to bring about a certain desired distribution of health (even where other legitimate goals would recommend distributing these goods in different ways). But even if they did believe that health was appropriately valued in this way, the resulting policy would be unattractive for a Rawlsian egalitarian liberal like Daniels. As Segall explains, the claim that health is special "mandates that entitlement to health care should not be curtailed due to inferior or superior wealth. ... But while this feature ('working both ways') appears attractive when it comes to medical care, it appears considerably less attractive with regard to the other social determinants of health. Egalitarians typically do want to allocate more (social bases of) selfrespect to those who have less of other goods (for example income, looks) and conversely, allocate more income to those who have smaller bundles (compared to others) of other social (and natural) assets. But treating the social determinants of health as special prohibits this.’[16]

Despite his claim that we should treat the social determinants of health as special, Daniels in fact seems to deny the position that this would commit 
him to. Not only does he deny that health is the most important good that a just society should be aiming at; he also denies that health should be a direct goal of justice. (As we said, he thinks that health is important for its effects on opportunity, and not for its own sake.) So it seems that there is a deep tension in Daniels's account of health and justice: he is committed both to the claim (a) that health is not a primary good and as such not itself part of what it is for a distribution to be just, and (b) the claim that health is special, and should set limits on what it is for a distribution to be just.

The broader point is that once we acknowledge that health has social determinants, which we have reason to care about for their own sake from the perspective of justice, quite apart from the effect they have on health, we cannot construct a theory of justice for health in isolation from a general theory of justice. Rather we need to embed our theory of justice for health in a broader general theory of justice, as Daniels acknowledges:

The premise of the pun in the title of Just Health Care was that I could explain what justice required in health care without talking about all of social justice. I only had to appeal to widespread agreement with the importance of equality of opportunity. In Just Health, that premise is undermined...[17]

Once we realise this, describing health (and the social determinants of 
health) as special does not seem very helpful, as it fudges a key question about how justice in health is related to a broader general theory of justice. What we need to know is how we should weigh health against other goods, such as income, liberty and the social bases of self-respect. Being told that health is special gives us little or no guidance, given that all these other goods are clearly important too.

From the perspective of justice we should care fundamentally about only those things which are of fundamental importance for justice, and we should care about other things only for the effect that they have on things that are of fundamental importance for justice. So a better place to start would be to ask whether health is of fundamental importance for justice, or does health matter only because of the effect that health has on other goods which are of fundamental importance for justice? As I see it this leaves Daniels with a choice. If he really wants to make good on the somewhat murky claim that health is special, then he should commit himself to the claim that health is a primary social good, which matters for its own sake when it comes to constructing a just society. Staying within the broadly Rawlsian framework within which he works, he could introduce the social bases of health as an additional Rawlsian primary good.[18]

This seems a reasonable extension of Rawls' theory, given that Rawls himself allows that health is equally as important a good as the primary goods which his theory of justice picks out to be distributed fairly.[19] 
Whilst Rawls denies that we should treat health as one of the primary goods, he does so on the grounds (a) that health is 'natural' rather than a social good (meaning that it is much less closely affected affected by changes in the basic structure of society than are the genuine primary goods such as rights, liberties and opportunities, income and wealth, and the social bases of self-respect), and (b) his theory of justice concerns only the justice of the basic structure of society.[20] This was a reasonable view of health for Rawls to hold in 1971, but the mass of literature produced on the social determinants of health over the past thirty years has clearly demonstrated that (a) is false. Whilst Rawls seems never to have revised his views to take into account the social determinants of health, and promote health to the status of a primary good, this would be an obvious option for anyone thinking about health and justice now.

Daniels suggests two reasons for resisting such a move, neither of which is convincing. The first is that if we increase our list of primary goods above those proposed by Rawls, we are likely to lose our overlapping consensus that these goods really are needs for living the life of a citizen. The second is that the more primary goods we have, the more difficult it will be to work out who is worst off. The first claim is unconvincing as a reason for thinking for refusing to treat health as a primary good, given that health is not contentious in this way. The second is also unconvincing, given that the problem of indexing occurs whenever we are trying to reconcile two or 
more incommensurable goods, and will be a problem for Rawls' theory whether or not we add health to the list of primary goods (as Daniels himself acknowledges).[21] Daniels does not provide an argument for why working out who is worst off, measured according to six incommensurable goods, will be significantly more difficult than doing so on the basis of five.

It might be that Daniels's real reason for objecting to health as a primary good is that he does not think that health is sufficiently important to merit this; that ultimately health is not of direct relevance for justice. If this is his view, he should explicitly adopt what Fabienne Peter calls an "indirect" approach to health and justice: namely one where we focus on making society as just as possible in conventional Rawlsian terms and then take injustices in health to be those that derive from social conditions which we have a prior reason for believing to be unjust.[22] Either way, framing his account in terms of the special moral importance of health merely muddies the waters. 


\section{CONCLUSION}

Whilst Daniels is to be congratulated for bringing the normative relevance of the literature on the social determinants of health to the attention of many in bioethics, the account of justice in health he arrives at is deeply problematic. Given that (as Daniels now acknowledges) we need a theory of justice for health and healthcare which is continuous with our general theories of justice, I suggest that it would be better to go back to the drawing board and start from the clearer question of whether health is of fundamental importance for justice than to continue to place any store by the question of whether health is 'special'.

\section{REFERENCES}

1. Daniels, N. Just Health. Cambridge: Cambridge University Press, 2007.

2. Daniels, N. Just Health Care. Cambridge: Cambridge University Press, 1985.

3. Daniels, N. Just Health. Cambridge: Cambridge University Press, 2007: 37.

4. Marmot, M. and Wilkinson R. Social determinants of health. The solid facts. Denmark: World Health Organisation, 2003.

5. Daniels, N. Just Health. Cambridge: Cambridge University Press, 2007: 18 .

6. Segall, S. Is Health Care (Still) Special? The Journal of Political 
Philosophy 2007;15(3):346.

7. Segall, S. Is Health Care (Still) Special? The Journal of Political Philosophy 2007;15(3):346.

8. Daniels, N. Just Health. Cambridge: Cambridge University Press, 2007: 57.

9. Daniels, N. Just Health. Cambridge: Cambridge University Press, 2007: 43.

10. Sorell, T. Moral Theory and Anomaly. Oxford: Blackwell, 2000: 5154.

11. Segall, S. Is Health Care (Still) Special? The Journal of Political Philosophy 2007;15(3):347-8.

12. Daniels, N. Just Health. Cambridge: Cambridge University Press, 2007:79.

13. Marmot, M. Status Syndrome: How Your Social Standing Directly Affects Your Health and Life Expectancy. London: Bloomsbury, 2004.

14. Wilkinson R. Unhealthy Societies: The Afflictions of Inequality. London: Routledge, 1996.

15. Daniels, N. Just Health. Cambridge: Cambridge University Press, 2007: 30 .

16. Segall, S. Is Health Care (Still) Special? The Journal of Political Philosophy 2007;15(3):360.

17. Daniels, N. Just Health. Cambridge: Cambridge University Press, 2007: 4.

18. Veatch, R. M. Justice, the Basic Social Contract and Health Care. In Contemporary Issues in Bioethics, 5th ed, eds. T. Beauchamp and L. Walters, pp. 368-74. Belmont, CA: Wadsworth, 1999.

19.

20. Rawls, J. A Theory of Justice. Cambridge, Mass.: Harvard University Press, 1971: 62.

21. Rawls, J. A Theory of Justice. Cambridge, Mass.: Harvard University Press, 1971: 62.

22. Daniels, N. Just Health. Cambridge: Cambridge University Press, 2007: 57.

23. Peter, F. Health Equity and Social Justice. Journal of Applied Philosophy, 2001;18(2):159-170. 